Check for updates

Cite this: RSC Adv., 2018, 8, 35226

Received 23rd August 2018 Accepted 3rd October 2018

DOI: $10.1039 / c 8 r a 07053 a$

rsc.li/rsc-advances

\section{Tunable transport and optoelectronic properties of monolayer black phosphorus by grafting $\mathrm{PdCl}_{2}$ quantum dots $\dagger$}

\author{
Cuicui Sun, (D) Yuxiu Wang, Yingjie Jiang, Zhao-Di Yang, Guiling Zhang* \\ and Yangyang $\mathrm{Hu}$ (iD*
}

The electronic, transport, and optoelectronic properties of monolayer black phosphorus (MLBP) are much influenced by grafting $\mathrm{PdCl}_{2}$ groups, demonstrated here by using density functional theory (DFT) and nonequilibrium Green's function (NEGF) as well as the Keldysh Nonequilibrium Green's Functions (KNEGF) methods. We find that the $\mathrm{PdCl}_{2}$ groups prefer to locate over the furrow site of MLBP and form a planar quadridentate structure of $\left(\mathrm{Cr}_{\mathrm{Cr}}^{\mathrm{Cl}_{-}} \mathrm{Pd}_{-}\right)$. The $\mathrm{PdCl}_{2}$ groups serve as quantum dots by introducing discrete flat levels between the MLBP valence band and the Fermi level $\left(E_{f}\right)$. The conductivity is much lowered after attaching $\mathrm{PdCl}_{2}$ quantum dots, due to the fact that the scattering effect of $\mathrm{PdCl}_{2}$ plays a major role in the process of electron transporting. A threshold voltage is found for the functionalized system with a large density of $\mathrm{PdCl}_{2}$ quantum dots, a valuable clue for exploring current switches. However, no evident threshold voltage is found for the pure MLBP. Electrons permeate easier through the armchair direction compared with the zigzag either in the pure MLBP or in the functionalized composites. More importantly, grafting $\mathrm{PdCl}_{2}$ quantum dots is very beneficial for enhancing photoresponse. The values of photoresponse for the modified species are about 20 times higher than the free MLBP. A significant photoresponse anisotropy is observed for both MLBP and $n \mathrm{PdCl}_{2}-\mathrm{BP}(n=1,2$, and 4), contrary to the conductivity, the zigzag direction shows much stronger photoresponse than the armchair. All of the aforementioned unique properties make these new two-dimensional (2D) MLBP based materials especially attractive for both electronic and optoelectronic devices.

\section{Introduction}

Inspired by the great achievements of graphene, twodimensional (2D) nanomaterials have received great attention in the fields of micro-/nano-electronics and optoelectronics due to their distinct confinement effect of electrons in two dimensions, ${ }^{1}$ strong in-plane covalent interactions, ${ }^{2}$ large lateral size ${ }^{3}$ high exposure of surface, ${ }^{4}$ and so forth. After graphene with zero band gap ${ }^{5}$ and molybdenum disulphide with relatively low carrier mobility, ${ }^{6}$ monolayer black phosphorus (MLBP) has emerged as an important member of $2 \mathrm{D}$ materials family ${ }^{7}$ in recent years. In this layer, each $\mathrm{P}$ atom bonds to three neighboring $\mathrm{P}$ atoms through $\mathrm{sp}^{3}$ hybridized orbitals forming warped hexagons in a nonplanar fashion. To date, many production methods for MLBP have been developed, including liquid

School of Materials Science and Engineering, College of Chemical and Environmental Engineering, Harbin University of Science and Technology, Harbin 150080, China. E-mail: guiling-002@163.com

$\dagger$ Electronic supplementary information (ESI) available. See DOI: 10.1039/c8ra07053a exfoliation, ${ }^{8-12} \mathrm{Ar}^{+}$plasma thinning process, ${ }^{13}$ photochemical etching, ${ }^{\mathbf{1 4}}$ and mechanical exfoliation, ${ }^{\mathbf{1 5}, \mathbf{1 6}}$ etc. Importantly, it has enormous potential to be used in high-performance electronic and optoelectronic devices because of its direct tunable band gap ranging from 0.3 to $2.0 \mathrm{eV},{ }^{17,18}$ high carrier mobility of $\sim 1000 \mathrm{~cm}^{2} \mathrm{~V}^{-1} \mathrm{~s}^{-1}$ at room temperature,,$^{7,17,19}$ and anisotropic optical characteristics ${ }^{\mathbf{2 0 , 2 1}}$ that could complement or exceed graphene and molybdenum disulphide in the next generation of novel devices.

In the electronic arrangement, the $\mathrm{P}$ atom with a valence shell configuration $3 \mathrm{~s}^{2} 3 \mathrm{p}^{3}$ has five valence electrons available for bonding, and the existence of the lone pair makes MLBP reactive to air. Functionalization is proved to be an controllable and effective method to not only improve the stability but also to enrich the property ${ }^{2,23}$ of $2 \mathrm{D}$ materials. Tunability of electronic properties of $2 \mathrm{D}$ materials is crucial for their practical applications in electronics and optoelectronics. Up to now, many functionalized 2D black phosphorus (BP) have been reported, such as metal/BP contact systems, ${ }^{24-27}$ alkali metal/ nonmetal atom doped $\mathrm{BP},{ }^{28-31}$ carbon nanotube/BP composites, ${ }^{32}$ as well as $\mathrm{hBN} / \mathrm{BP}^{33-35}$ and $\mathrm{MoS}_{2} / \mathrm{BP}^{36,37}$ heterojunctions. 
Out of the above mentioned series, the most recent addition to the family are the functionalization of $\mathrm{BP}^{38,39}$ by adsorbing transition metal atoms on surface. ${ }^{40-44}$ It has been found that palladium (Pd) adatom adsorption on MLBP presents excellent electronic and optoelectronic behaviors. ${ }^{41-43}$ Up to now, research on functionalization of MLBP is predominantly focused on its physical modification; far less information is available regarding chemical modification, which is determined to be efficient in manipulating electronic and optoelectronic properties. $^{45}$

In general, the Pd atom is a typical transition metal for coordinating $\mathrm{P}$ and $\mathrm{Cl}$ ligands. ${ }^{46-48}$ These complexes have shown wide spread applications in electronics, photoelectrochemistry, and electrochemistry. ${ }^{49-51}$ Usually, Pd has a $4 \mathrm{~d}^{10}$ configuration and preferentially provides a $\mathrm{dsp}^{2}$ hybrid environment to coordinate with four ligands, i.e., forms a planar quadridentate complex. The exposed $\mathrm{P}$ atoms of MLBP are perfect ligands by providing lone pair electrons to coordinate with the Pd atom of $\mathrm{PdCl}_{2}$ to form a planar quadridentate structure of $\left(\left[\begin{array}{ll}\mathrm{Cl}_{-} \\ \mathrm{Pd}_{\mathrm{P}}\end{array}\right)\right.$. Of particular interest in this paper is investigation of covalent functionalization of MLBP with $\mathrm{PdCl}_{2}$ groups including the effects of $\mathrm{PdCl}_{2}$ on electronic, transport, and optoelectronic properties.

\section{Models and computational methods}

For the periodic systems, we constructed the supercell as $2 \times 4$ $(x \times y)$ containing $32 \mathrm{P}$ atoms (Fig. 1). We selected $n \mathrm{PdCl}_{2}$ groups (referred as $n \mathrm{PdCl}_{2}$, where $n=1,2$, and 4) to graft MLBP per supercell to study the effects of grafting density $n$. Hereafter, the functioned structures are denoted as $n \mathrm{PdCl}_{2}$-BP $(n=1,2$, and 4) for simplification. For the geometrical optimization, the $\mathrm{PdCl}_{2}$ was put at each adsorption site with all the atomic coordinates in the system being relaxed. The maximum force and maximum stress were set to the same value of $0.02 \mathrm{eV} \AA^{-1}$.
It has been reported that the MLBP displays anisotropic properties due to its anisotropic structure, ${ }^{52,53}$ which triggered us to calculate transport and optoelectronic properties for two mutually perpendicular directions, i.e., the armchair and zigzag directions (Fig. 2(a and c) vs. 2(b and d)). So we curved a nearly square plane $(\sim 26.04 \AA \times 26.50 \AA)$ of $\mathrm{MLBP}$ and $n \mathrm{PdCl}_{2}$-BP $(n=$ 1,2 , and 4 ) as the scatter region to be sandwiched between two $\mathrm{Au}(100)-(9 \times 3)$ electrodes to build two-probe devices. Such scatter region was formed by repeating each optimized supercell 3 times at the armchair direction and 2 times at the zigzag direction. When the scatter region used the zigzag edge to connect with the Au electrodes, the armchair direction properties were calculated (denoted as a-MLBP and a- $n \mathrm{PdCl}_{2}-\mathrm{BP}(n=1$, 2 , and 4)). Another was just the reverse (nominated as z-MLBP and $\mathrm{z}-n \mathrm{PdCl}_{2}-\mathrm{BP}(n=1,2$, and 4$\left.)\right)$. As a benchmark test, the $E_{\mathrm{f}}$ positions of the two-probe systems with two or four buffer layers of $\mathrm{Au}$ were calculated at $0.0 \mathrm{~V}$. We found that the $E_{\mathrm{f}}$ were almost locate at the same positions for the two cases $(-3.533772$ and $-3.533858 \mathrm{eV}$ for the two and four buffer layers, respectively). So we used two buffer layers of $\mathrm{Au}$ to perform further calculations. The nearest $\mathrm{P}-\mathrm{Au}$ distance is $2.37 \AA$, corresponding to their covalent bonding. ${ }^{54}$ Transport current was computed by changing the applied bias voltage in the step of $0.2 \mathrm{~V}$ in the range of -1.0 to $1.0 \mathrm{~V}$.

Electronic and transport property computations were performed by using the software package Atomistix ToolKit $(\mathrm{ATK})^{55-58}$ based on a basis of the combination of density function theory (DFT) and non-equilibrium Green's function (NEGF) methods. The on-site correlation effect among $4 \mathrm{~d}$ electrons of the Pd atom was accounted for by using the GGA+U scheme ${ }^{58}$ where the parameter U-J was set to be 6.0 based on the literature (6.0), ${ }^{59}$ which was also close to that (5.77) in the ATK_U database. The Perdew-Burke-Ernzerhof (PBE) exchange-correlation functional was employed. A single- $\zeta$ basis with polarization $(\mathrm{SZP})$ was used for all atoms. A $(7 \times 5 \times 1) K$-point in the Brillouin zone ( $x, y$, and $z$ directions, respectively) was adopted, and 150 Ry cutoff energy was applied to describe the periodic wave function.

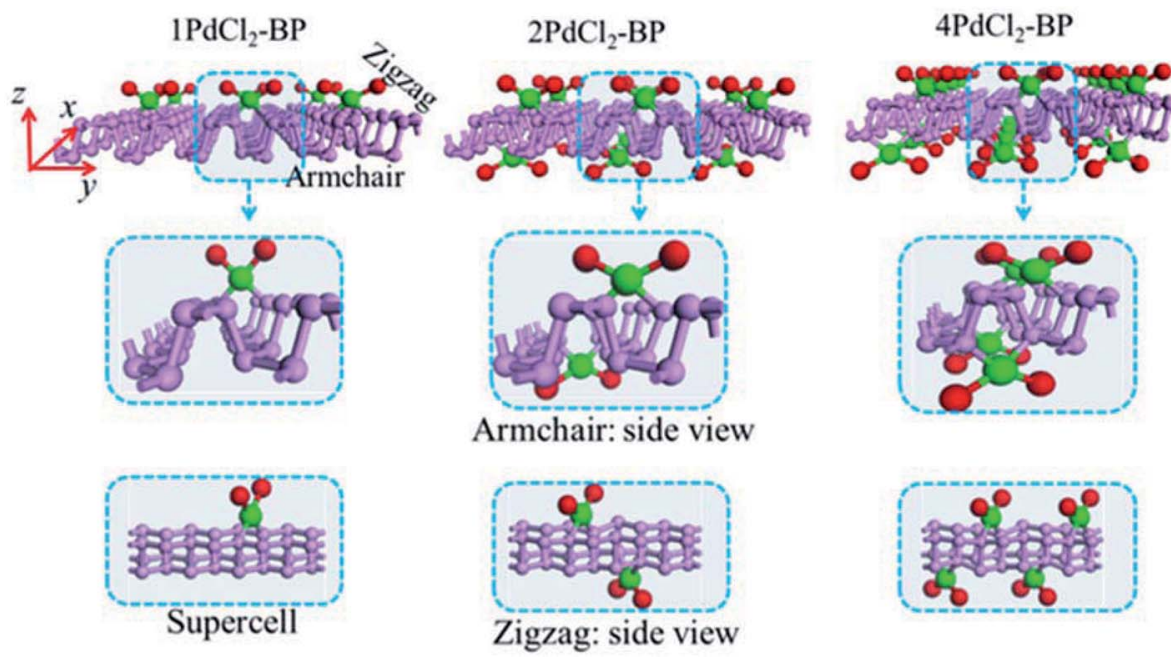

Fig. 1 Optimized structures of three most stable systems of $1 \mathrm{PdCl}_{2}-\mathrm{BP}, 2 \mathrm{PdCl}_{2}-\mathrm{BP}$, and $4 \mathrm{PdCl}_{2}-\mathrm{BP}$. 


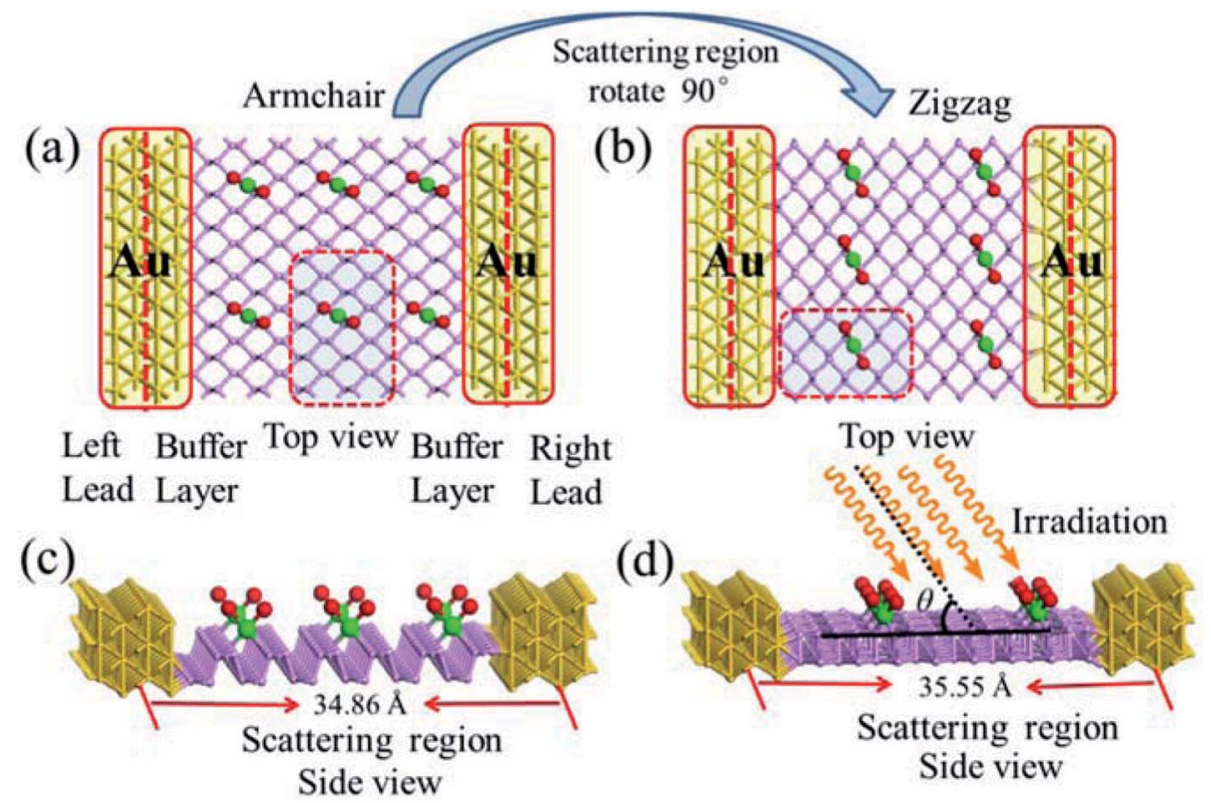

Fig. 2 Exemplified two-probe devices by $1 \mathrm{PdCl}-\mathrm{BP}$. (a) Top view of a-1PdCl$-\mathrm{BP}$; (b) top view of $\mathrm{z}-1 \mathrm{PdCl} 2-\mathrm{BP}$; (c) side view of a-1PdCl $2-B P$; (d) side view of $\mathrm{z}-1 \mathrm{PdCl}_{2}-\mathrm{BP}$. Irradiation on the scatter regions of two-probe devices are schematically shown in (d).

To gain an insight into the optoelectronic properties of MLBP and $n \mathrm{PdCl}_{2}$-BP $(n=1,2$, and 4$)$, we irradiated the scatter regions of above mentioned two-probe systems with linearly polarized light (exemplified as Fig. 2(d)). The polarized angle $\theta$ was assigned between the scatter region plane and the irradiation direction. The photo energy was set from 0.0 to $1.0 \mathrm{eV}$ with an interval of $0.1 \mathrm{eV}$. We calculated the photocurrent varying with $\theta$ from $0^{\circ}$ to $180^{\circ}$ at the $0.0 \mathrm{~V}$ bias voltage.

The optoelectronic properties of a-MLBP, z-MLBP, a- $n \mathrm{PdCl}_{2^{-}}$ $\mathrm{BP}$, and $\mathrm{z}-n \mathrm{PdCl}_{2}-\mathrm{BP}(n=1,2$, and 4$)$ were evaluated using the Nanodcal ${ }^{60}$ package which carried out DFT within the Keldysh Nonequilibrium Green's Functions (KNEGF). ${ }^{60,61}$ Standard norm-conserving nonlocal pseudopotentials were adopted to define the atomic cores, and SZP linear combination of atomic orbital basis set was used to expand physical quantities. The exchange-correlation potential was treated at the GGA+U with PBE.

\section{Results and discussions}

\subsection{Stability and geometry}

The MLBP is not residing in a flatland, instead, it forms a puckered hexagonal structure. The optimized supercell vectors of MLBP and $n \mathrm{PdCl}_{2}$-BP $(n=1,2$, and 4$)$ were supplied in Table $\mathrm{S} 1$ in the ESI. $\dagger$ On the surface of this supercell one, two, or four $\mathrm{PdCl}_{2}$, corresponding to $n=1,2$, or 4 , respectively, are considered to coordinate with the $\mathrm{P}$ atom for investigating the effect of grafting density. Taking into account all the circumstances, 20 configurations are computed for $n \mathrm{PdCl}_{2}-\mathrm{BP}(n=1,2$, and 4), i.e., 2 for $1 \mathrm{PdCl}_{2}-\mathrm{BP}, 10$ for $2 \mathrm{PdCl}_{2}-\mathrm{BP}$, and 8 for $4 \mathrm{PdCl}_{2}-$ BP. Table S2 in the ESI $\dagger$ summarizes the optimized total energies of supercells of these 20 configurations. We find that the $\mathrm{PdCl}_{2}$ groups prefer to locate over the furrow site rather than upon the ridge position of the MLBP as the former has lower total energy than the latter. A planar structure of $\left(\mathrm{Cr}_{\mathrm{Cr}_{\mathrm{P}}}^{\mathrm{Cr}_{-}}\right)$is formed in these $n \mathrm{PdCl}_{2}$-BP complexes, a typical quadridentate structure for $\mathrm{Pd}$. As for $2 \mathrm{PdCl}_{2}-\mathrm{BP}$ and $4 \mathrm{PdCl}_{2}-\mathrm{BP}$, the $\mathrm{PdCl}_{2}$ components tend to evenly and staggerly distributed on both sides of MLBP. Finally, we chose three most stable configurations for $n=1,2$, and 4, respectively, as given in Fig. 1, to further investigate the electronic, transport, and optoelectronic properties.

For the three most stable structures of $1 \mathrm{PdCl}_{2}-\mathrm{BP}, 2 \mathrm{PdCl}_{2}-\mathrm{BP}$, and $4 \mathrm{PdCl}_{2}-\mathrm{BP}$, we have calculated the binding energies, $E_{\mathrm{b}}$, by using $E_{\mathrm{b}}=E_{n \mathrm{PdCl}_{2}-\mathrm{BP}}-E_{\mathrm{MLBP}}-n E_{\mathrm{PdCl}_{2}}$, where $E_{n \mathrm{PdCl}_{2}-\mathrm{BP}}, E_{\mathrm{MLBP}}$, and $E_{\mathrm{PdCl}_{2}}$ denote the total energies of the functioned systems, pristine MLBP, and $\mathrm{PdCl}_{2}$ in the unit cell, respectively. For the $\mathrm{PdCl}_{2}$ calculation, the unit cell was set to be $30 \times 30 \times 30 \AA$, so that $\mathrm{PdCl}_{2}$ can be viewed as an isolated system. The calculated binding energies are all negative with increasing exoenergic values of $-1.95,-3.83$, and $-7.35 \mathrm{eV}$ from $n=1,2$ to 4 (Table 1 ), demonstrating that grafting $\mathrm{PdCl}_{2}$ groups to the MLBP surface is energetically favorable.

After optimizing, the $\mathrm{P}-\mathrm{P}, \mathrm{Pd}-\mathrm{P}, \mathrm{Pd}-\mathrm{Cl}$, and $\mathrm{Pd}-\mathrm{Pd}$ bond lengths as well as the $\mathrm{Cl}-\mathrm{Cl}$ distances for MLBP and $n \mathrm{PdCl}_{2}-\mathrm{BP}$ $(n=1,2$, and 4$)$ are collected in Table 1. MLBP consists of double puckered planes; each atom is bound to two in-plane atoms with a bond length of $r_{\mathrm{P}-\mathrm{P}}^{\mathrm{in}}=2.224 \AA$ and to one out-ofplane atom with a bond length of $r_{\mathrm{P}-\mathrm{P}}^{\text {out }}=2.244 \AA$, fully in agreement with experimental observation. ${ }^{62}$ For $n \mathrm{PdCl}_{2}$-BP $(n=$

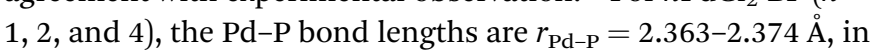
line with genral Pd-P chemical bond lengths calculated by M. A. Carvajal et al. $^{63}(2.221-2.476 \AA$ $)$ and experimental data reported by V. I. Bakhmutov et al. $(2.290-2.520 \AA) .{ }^{47}$ This shows that the 
Table 1 Calculated binding energies $E_{\mathrm{b}}$ and geometries for $\mathrm{MLBP}$ and $n \mathrm{PdCl}_{2}-\mathrm{BP}(n=1,2$, and 4)

\begin{tabular}{|c|c|c|c|c|c|c|c|}
\hline Species & $E_{\mathrm{b}}(\mathrm{eV})$ & $r_{\mathrm{P}-\mathrm{P}}^{\mathrm{in}}(\AA)$ & $r_{\mathrm{P}-\mathrm{P}}^{\text {out }}(\AA)$ & $r_{\mathrm{Pd}-\mathrm{P}}(\AA)$ & $r_{\mathrm{Pd}-\mathrm{Cl}}(\AA)$ & $D_{\text {Pd-Pd }}(\AA)$ & $D_{\mathrm{Cl}-\mathrm{Cl}}(\AA)$ \\
\hline MLBP & - & 2.224 & 2.244 & - & - & - & - \\
\hline $1 \mathrm{PdCl}_{2}-\mathrm{BP}$ & -1.95 & 2.264 & 2.307 & 2.363 & 2.447 & - & - \\
\hline $4 \mathrm{PdCl}_{2}-\mathrm{BP}$ & -7.35 & 2.271 & 2.365 & 2.373 & 2.438 & 6.627 & 6.205 \\
\hline
\end{tabular}

covalent bonds are formed between grafted $\mathrm{PdCl}_{2}$ groups and the $\mathrm{P}$ atoms. These $\mathrm{P}$ atoms (bonded to $\mathrm{Pd}$ ) are pushed slightly inward (toward another plane), consequently, the $r_{\mathrm{P}-\mathrm{P}}^{\text {in }}$ and $r_{\mathrm{P}-\mathrm{P}}^{\text {out }}$ are elongated to 2.264-2.271 $\AA$ and 2.307-2.365 $\AA$, respectively. The Pd-Cl bond lengths in $n \mathrm{PdCl}_{2}-\mathrm{BP}(n=1,2$, and 4) are about $r_{\mathrm{Pd}-\mathrm{Cl}}=2.429-2.457 \AA$, in accordance with literature reported values of $2.333-2.575 \AA .{ }^{63}$ For $n \mathrm{PdCl}_{2}-\mathrm{BP}(n=$ $1,2$, and 4$)$, the nearest $\mathrm{Cl}-\mathrm{Cl}$ distances $\left(D_{\mathrm{Cl}-\mathrm{Cl}}\right)$ or $\mathrm{Pd}-\mathrm{Pd}$ distances $\left(D_{\mathrm{Pd}-\mathrm{Pd}}\right)$ between two adjacent $\mathrm{PdCl}_{2}$ are all longer than $6.0 \AA$, implying negligible $\mathrm{PdCl}_{2}-\mathrm{PdCl}_{2}$ interactions in these considered systems.

\subsection{Band structure}

The band structure and projected density of states (PDOS) as well as the Kohn-Sham orbitals near the Fermi level $\left(E_{\mathrm{f}}\right)$ of MLBP and $n \mathrm{PdCl}_{2}-\mathrm{BP}(n=1,2$, and 4$)$ were calculated as shown in Fig. 3 and 4. Clearly, the MLBP shows a semiconductive feature with a direct band gap $\left(E_{\mathrm{g}}\right)$ of $0.85 \mathrm{eV}$, in agreement with the previous report value about $0.90 \mathrm{eV}^{64-66}$ Decoration of $\mathrm{PdCl}_{2}$ groups on MLBP surface can tune the transport property by altering the electronic structure. They may carry properties exhibited by each component as well as new properties generated as a result of their combination.

We can evidently find that $n \mathrm{PdCl}_{2}$-BP introduces flat $\mathrm{PdCl}_{2}$ bands just above the MLBP valence band and below the $E_{\mathrm{f}}$, indicating that the $\mathrm{PdCl}_{2}$ groups contribute localized states in the MLBP band gap region. The Kohn-Sham orbitals also clearly demonstrate the localized character of $\mathrm{PdCl}_{2}$ groups. The dispersion of some $\mathrm{PdCl}_{2}$ band structures around the $\Gamma$ may be attributed to the large interaction between the $\mathrm{Pd}$ and $\mathrm{Cl}$ atoms. Correspondingly, $\mathrm{PdCl}_{2}$ groups give sharp PDOS peaks as localized valence states. In this sense, the anchored $\mathrm{PdCl}_{2}$ groups behave as quantum dots. These quantum dots mainly originate from the $\mathrm{Cl}-3 \mathrm{p}$ state as can be seen from its large PDOS. In general, quantum dots can form ionic like or covalent like interaction. ${ }^{67}$ In the former case, the electrons are localized on the individual dots which exhibit a weak tunnel coupling. For the latter, quantum dot electron states are quantummechanically coupled and show strong tunnel coupling. Clearly, $n \mathrm{PdCl}_{2}-\mathrm{BP}(n=1,2$, and 4$)$ systems bear spatially separated $\mathrm{PdCl}_{2}$ quantum dots with localized and discrete energy levels owing to the large separations between $\mathrm{PdCl}_{2}$ quantum dots, electron tunneling through direct coupling of $\mathrm{PdCl}_{2}$ is minor.

For a general planar quadridentate complex, the ligand field splitting of the Pd $4 \mathrm{~d}$ electrons results in molecular orbitals being formed of principally a character of $\mathrm{e}_{\mathrm{g}}\left(\mathrm{d}_{y z, z x}\right), \mathrm{a}_{1 \mathrm{~g}}\left(\mathrm{~d}_{z^{2}}\right), \mathrm{b}_{2 \mathrm{~g}}$ $\left(\mathrm{d}_{x y}\right)$, and $\mathrm{b}_{1 \mathrm{~g}}\left(\mathrm{~d}_{x^{2}-y^{2}}\right)$. The former $\mathrm{e}_{\mathrm{g}}\left(\mathrm{d}_{y z, z x}\right)$ and $\mathrm{a}_{1 \mathrm{~g}}\left(\mathrm{~d}_{z^{2}}\right)$ are electron occupied leaving $\mathrm{b}_{2 g}\left(\mathrm{~d}_{x y}\right)$ and $\mathrm{b}_{1 g}\left(\mathrm{~d}_{x^{2}-y^{2}}\right)$ to be unoccupied. We can see from the PDOS, clearly, the $\mathrm{e}_{\mathrm{g}}\left(\mathrm{d}_{y z, z x}\right)$ molecular orbitals locate just below the $E_{\mathrm{f}}$. Usually, the Pd quadridentate compounds belong to inner-orbital complexes with a zero magnetic moment. In $n \mathrm{PdCl}_{2}-\mathrm{BP}$, the $\mathrm{Cl}_{2} \mathrm{P}_{2}$ ligands generate an uneven ligand field leading to a so-called JahnTeller effect. Pd forms a dsp ${ }^{2}$ hybrid environment to interact with the $3 \mathrm{p}$ orbitals of the $\mathrm{P}$ and $\mathrm{Cl}$ atoms. As a result, the

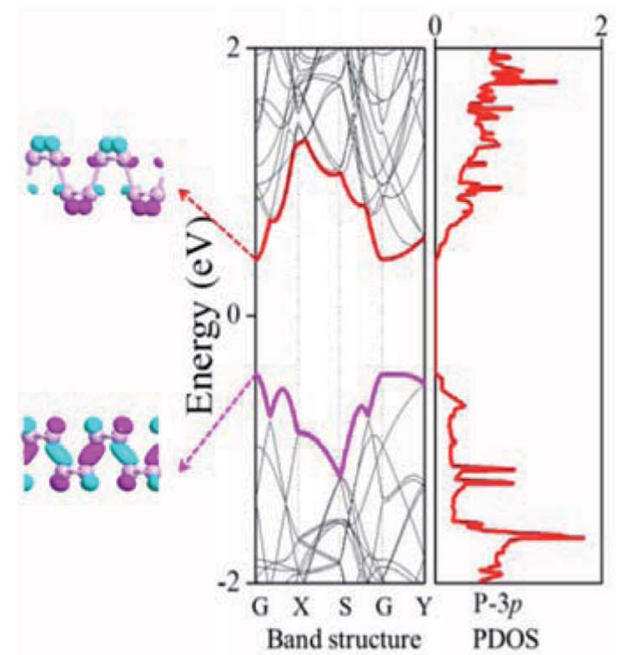

(a) MLBP
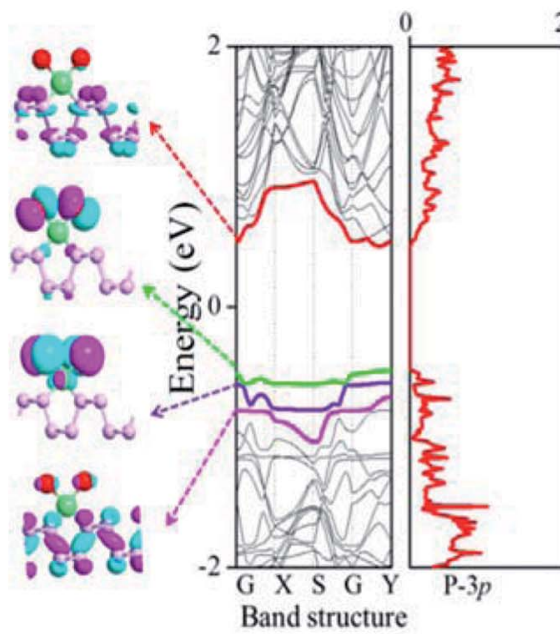

(b) $\quad \mathrm{PdCl}_{2}-\mathrm{BP}$

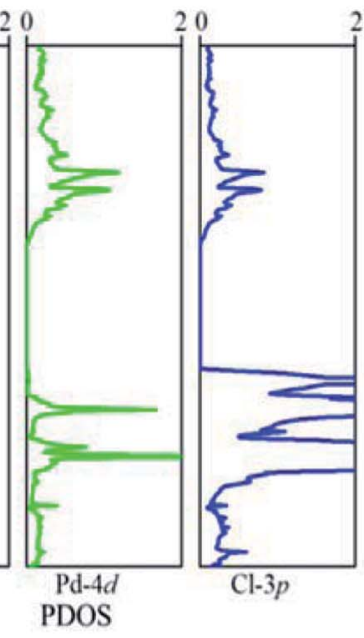

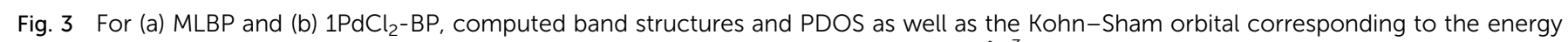
levels (highlighted in color lines) near $E_{f}$ at the $\Gamma$ point. The iso-surface value is $0.028\left(e \AA^{-3}\right)$. 


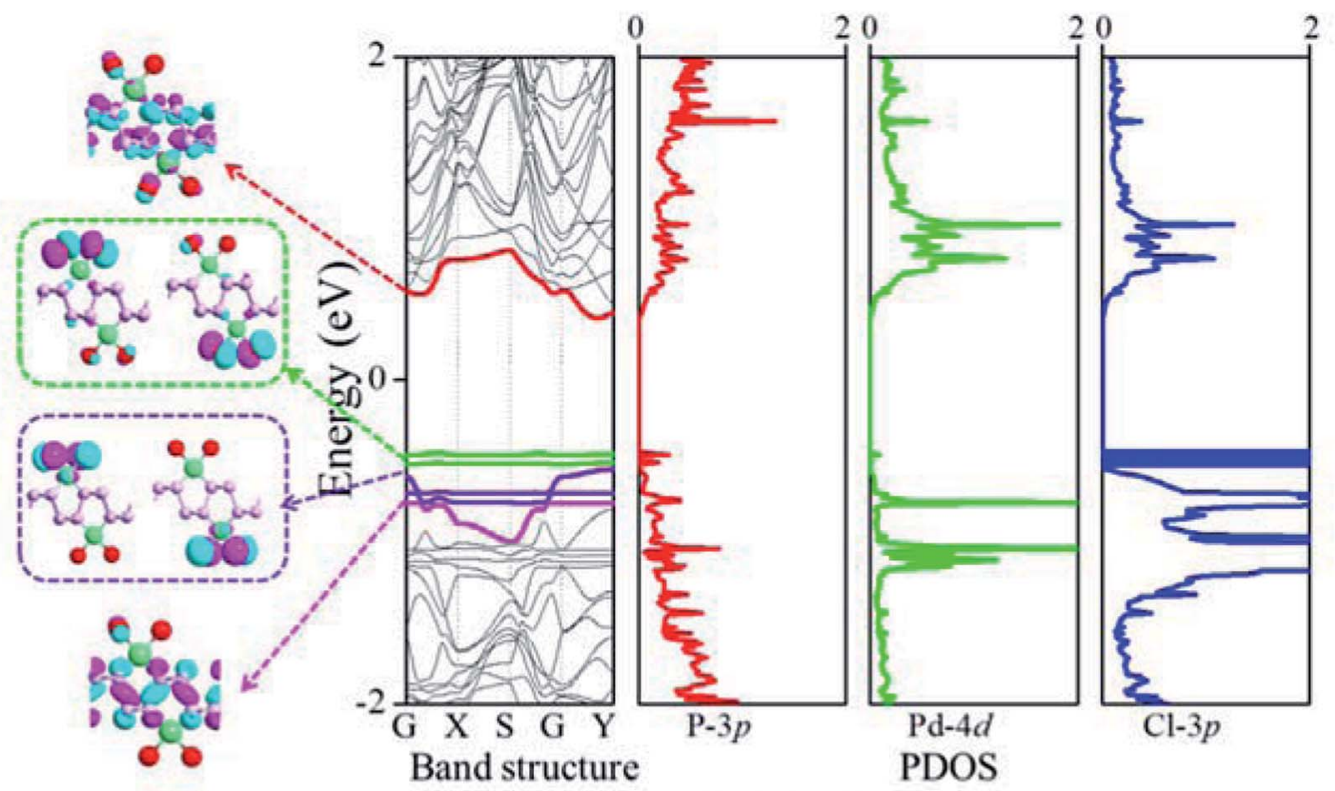

(a) $2 \mathrm{PdCl}_{2}-\mathrm{BP}$

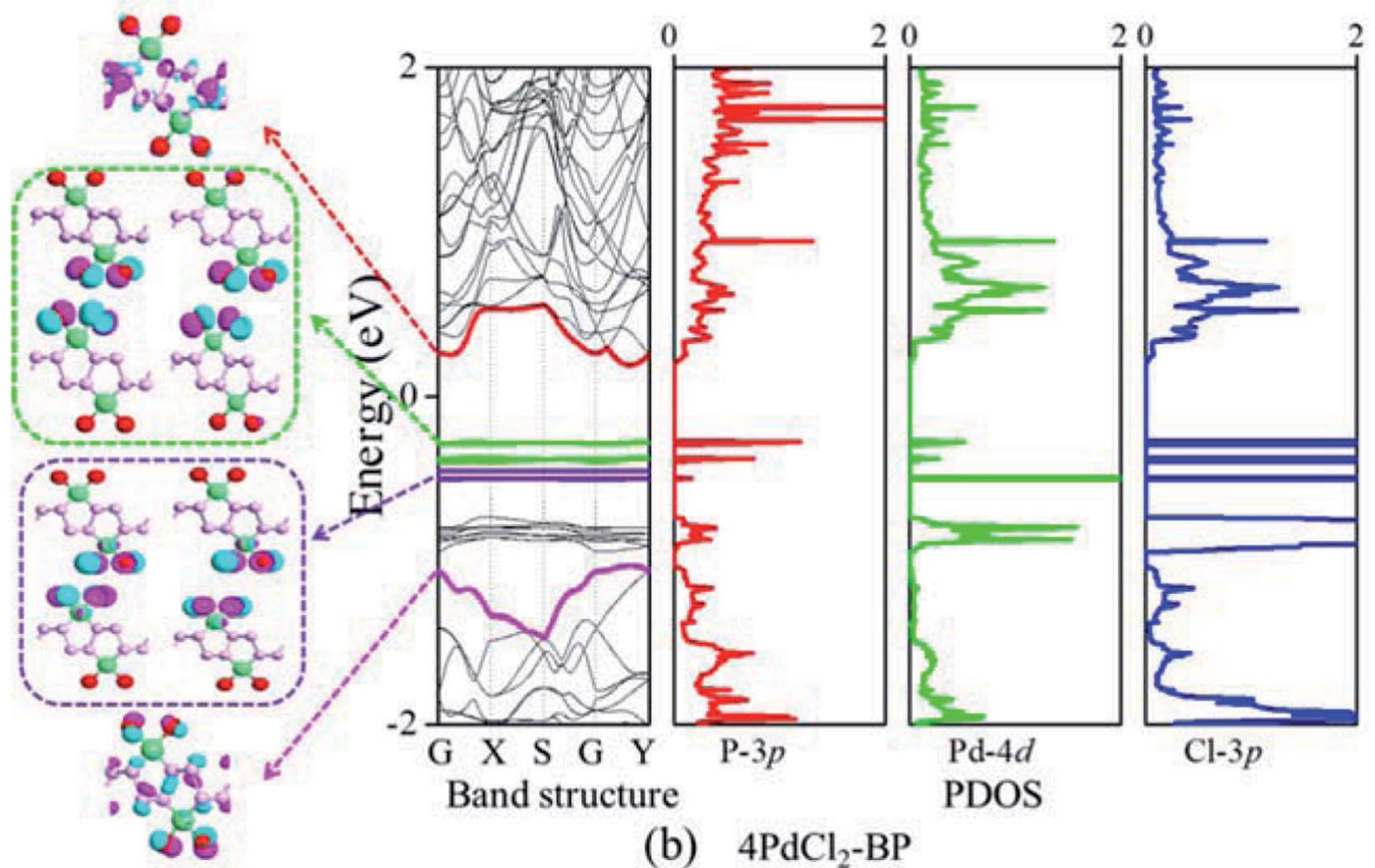

Fig. 4 For (a) $2 \mathrm{PdCl}_{2}-\mathrm{BP}$ and (b) $4 \mathrm{PdCl}_{2}-\mathrm{BP}$, computed band structures and PDOS as well as the Kohn-Sham orbital corresponding to the energy levels (highlighted in color lines) near $E_{f}$ at the $\Gamma$ point. The iso-surface value is $0.028\left(e \AA^{-3}\right)$.

degenerate orbitals of $\mathrm{e}_{\mathrm{g}}\left(\mathrm{d}_{y z, z x}\right)$ are again split. Therefore, discrete bands appear in the MLBP band gap region of $n \mathrm{PdCl}_{2}$ $\mathrm{BP}(n=1,2$, and 4$)$.

To further investigate the interactions between MLBP and $\mathrm{PdCl}_{2}$, we calculated the electron difference densities for $n \mathrm{PdCl}_{2}-\mathrm{BP}(n=1,2$, and 4$)$ systems and the results are plotted in Fig. 5. The electron difference density refers to the difference between the self-consistent valence charge density and the superposition of atomic valence density, which indicates the coupling between the atoms in a certain system. The green area means no electron transfer, red part represents obtaining electrons, while blue region indicates losing electrons. Charge transfers from the MLBP substrate to the $\mathrm{PdCl}_{2}$ quantum dots can be observed from Fig. 5, suggesting a strong coupling between MLBP and $\mathrm{PdCl}_{2}$, which is an important factor in tuning the electronic and optoelectronic properties.

The $n \mathrm{PdCl}_{2}$-BP composites show p-type characteristics accompanied by the appearance of two kinds of midgap energy levels below the $E_{\mathrm{f}}$ (green and purple lines in Fig. 3 and 4). The higher one is close to the $E_{\mathrm{f}}$ and dominated by the Cl-3p state while the lower one is controlled by the Pd- $4 \mathrm{~d}$ state. The MLBP valence band is buried under the $\mathrm{PdCl}_{2}$ midgap energy levels 


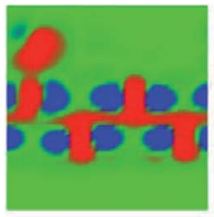

$1 \mathrm{PdCl}_{2}-\mathrm{BP}$

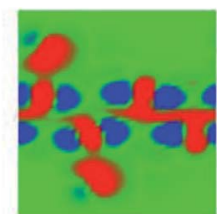

$2 \mathrm{PdCl}_{2}-\mathrm{BP}$

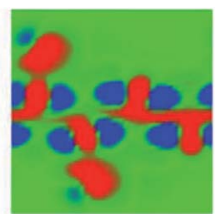

$4 \mathrm{PdCl}_{2}-\mathrm{BP}$
$-0.005$

0

0.005

Fig. 5 Computed electron difference densities of $1 \mathrm{PdCl}_{2}-\mathrm{BP}, 2 \mathrm{PdCl}_{2}$ $\mathrm{BP}$, and $4 \mathrm{PdCl}_{2}-\mathrm{BP}$. The green area means no electron transfer, red part represents obtaining electrons, while blue region indicates losing electrons.

and hybrids to some extent with $\mathrm{Pd}-4 \mathrm{~d} / \mathrm{Cl}-3 \mathrm{p}$. Therefore, electrons can be transferred from the MLBP substrate to the $\mathrm{PdCl}_{2}$ quantum dots owing to the strong electronegativity of the $\mathrm{Cl}$ atom. The substrate MLBP and the appendant $\mathrm{PdCl}_{2}$ groups in $n \mathrm{PdCl}_{2}$ - $\mathrm{BP}$ all contribute to the conduction band. The band gap values of MLBP in $n \mathrm{PdCl}_{2}$-BP do not bring much change relative to the pure MLBP, varying from 1.14 to $1.22 \mathrm{eV}$. However, the MLBP in $n \mathrm{PdCl}_{2}$-BP becomes to an indirect band gap semiconductor due to the orbital coupling of $\mathrm{P}$ with $\mathrm{PdCl}_{2}$, different from the direct feature in the pristine MLBP. In this case, the $\mathrm{PdCl}_{2}$ quantum dots play two-fold effects on the transport property. On one hand, they offer extra valence electrons to be excited to the conduction bands to participate in transporting which is beneficial for enhancing the conductivity. On the other hand, the electron excitation of $\mathrm{PdCl}_{2}$ midgap levels leaves holes for trapping electrons from MLBP, that is, $\mathrm{PdCl}_{2}$ quantum dots behave as additional scattering centers which degrade the mobility of the charge carriers. This is useful for devices which require fast switch off times. ${ }^{68}$ From the analysis above, it is concluded that the $\mathrm{PdCl}_{2}$ quantum dots exert an important effect in electron transporting, furthermore, such influence becomes more significant with the increasing grafting density $n$. This can be further confirmed by the calculated transport properties as addressed in the following section.

\subsection{Transport property}

To compute the electron transport properties of MLBP and $n \mathrm{PdCl}_{2}-\mathrm{BP}(n=1,2$, and 4$)$, the two-probe devices were constructed by sandwiching a curved $2 \mathrm{D}$ structure $(26.05 \AA \times 26.51$ $\AA)$ of MLBP and $n \mathrm{PdCl}_{2}-\mathrm{BP}(n=1,2$, and 4$)$ between two $\mathrm{Au}$ electrodes as shown by Fig. 2 . The current $I$ through the scatter region was calculated based on the formula (1): $:^{57}$

$$
I=\frac{2 e^{2}}{h} \int_{-\infty}^{\infty}\left[f\left(E(V)-\mu_{\mathrm{L}}(V)\right)-f\left(E(V)-\mu_{\mathrm{R}}(V)\right)\right] T(E, V) \mathrm{d} E
$$

where $f$ is the Fermi function; $\mu_{\mathrm{L}(\mathrm{R})}$ is the chemical potentials of left (right) electrode; $T(E, V)$ is the transmission function for electrons with energy $E$ at certain bias $V$.

The transmissions along the armchair (a- $\left.n \mathrm{PdCl}_{2}-\mathrm{BP}\right)$ and zigzag $\left(\mathrm{z}-n \mathrm{PdCl}_{2}-\mathrm{BP}\right)$ directions are both considered. The calculated current-voltage $(I-V)$ curves are given in Fig. 6 . As for MLBP, electrons permeate easier through the armchair direction compared with the zigzag. For instance, at $-1.0 \mathrm{~V}$ bias voltage, the current magnitude of a-MLBP is $-28.88 \mu \mathrm{A}$, while it goes down to $-13.03 \mu \mathrm{A}$ in the z-MLBP device. This anisotropic phenomenon is still preserved after being pinned with $\mathrm{PdCl}_{2}$ quantum dots. For example, under $-1.0 \mathrm{~V}$ bias voltage, a$4 \mathrm{PdCl}_{2}$-BP gives a current of $-10.01 \mu \mathrm{A}$ while $\mathrm{z}-4 \mathrm{PdCl}_{2}-\mathrm{BP}$ presents a lower data of $-2.82 \mu \mathrm{A}$. It is noteworthy that grafting $\mathrm{PdCl}_{2}$ quantum dots to the MLBP surface could significantly influence the transport properties. On one hand, the conductivity is much lowered after anchoring $\mathrm{PdCl}_{2}$ quantum dots, and the current magnitudes at a certain bias voltage follow the sequence of $\mathrm{MLBP}>1 \mathrm{PdCl}_{2}-\mathrm{BP}>2 \mathrm{PdCl}_{2}-\mathrm{BP}>4 \mathrm{PdCl}_{2}-\mathrm{BP}$, indicating that the scatter effect of $\mathrm{PdCl}_{2}$ plays a major role in the process of electron transporting. On the other hand, the threshold voltage becomes more and more distinct with the increasing grafting density $n$. Pure MLBP shows continuously rising current from 0.2 to $1.0 \mathrm{~V}$ bias voltage, no evident threshold voltage is found. Turn to $4 \mathrm{PdCl}_{2}-\mathrm{BP}$, off-state is kept until the applied bias reaches to $\pm 0.8 \mathrm{~V}$, on-state begins at $\pm 1.0 \mathrm{~V}$ bias voltage. Prospectively, grafting MLBP with a large

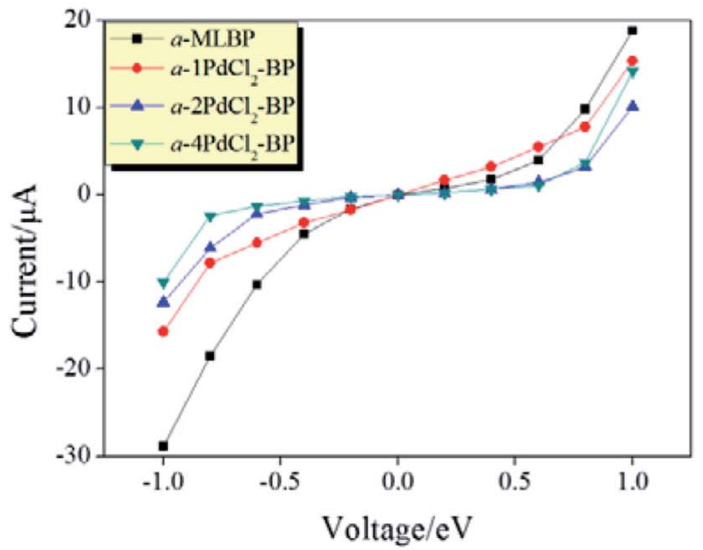

(a) Along armchair direction

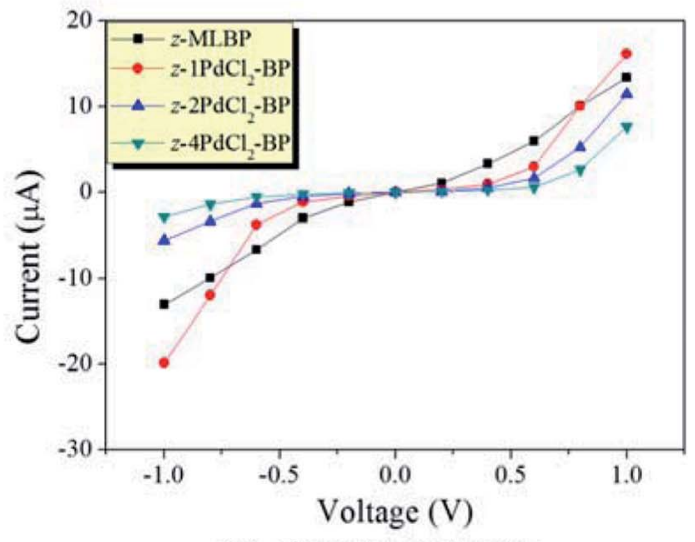

(b) Along zigzag direction

Fig. 6 Computed $I-V$ curves for MLBP and $n \mathrm{PdCl}_{2}-\mathrm{BP}(n=1,2$, and 4$)$ two-probe devices. (a) Transport along the armchair direction, and (b) transport along the zigzag direction. 


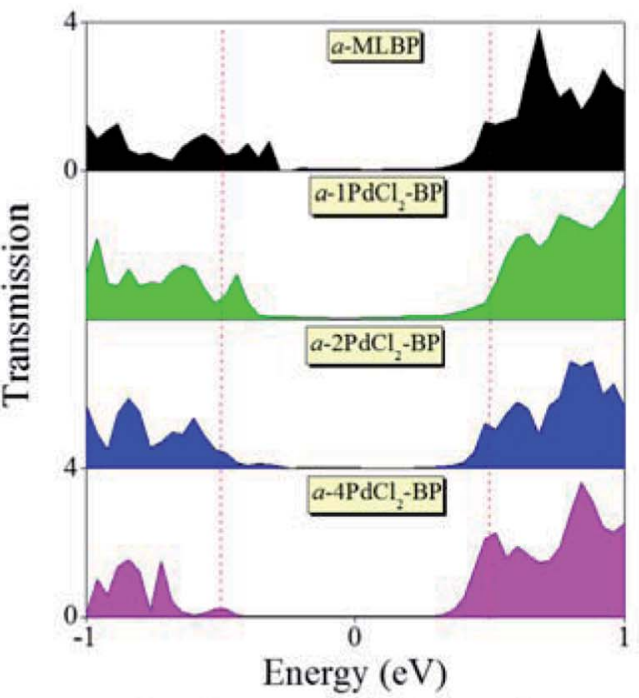

(a) Along armchair direction

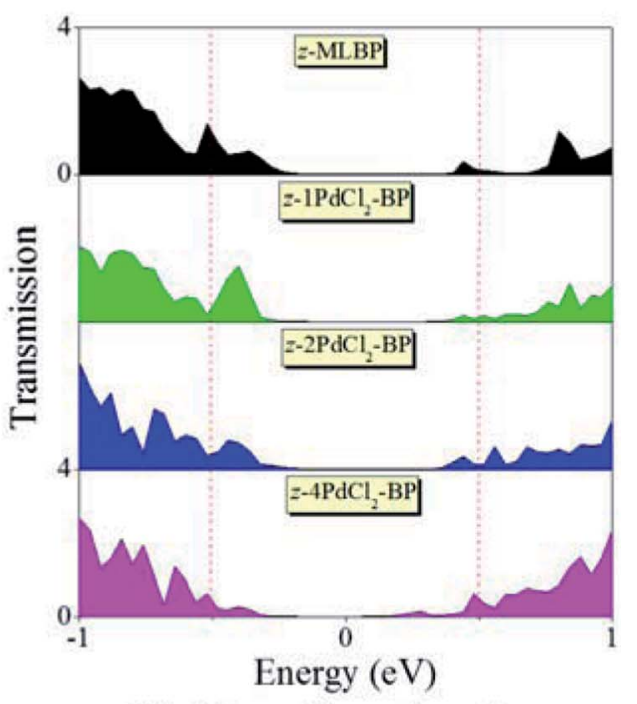

(b) Along zigzag direction

Fig. 7 Transmission spectra of $\mathrm{MLBP}$ and $n \mathrm{PdCl}_{2}-\mathrm{BP}(n=1,2$, and 4$)$ two-probe devices at $1.0 \mathrm{~V}$ bias voltage. (a) Transport along the armchair direction, and (b) transport along the zigzag direction. Red dashed lines indicate the bias window.

density of $\mathrm{PdCl}_{2}$ quantum dots paves a new way toward achieving electronic switch devices.

To further shed light on effects of the $\mathrm{PdCl}_{2}$ grafting upon the transport properties, the transmission spectra (TS) for MLBP and $n \mathrm{PdCl}_{2}-\mathrm{BP}(n=1,2$, and 4$)$ at $1.0 \mathrm{~V}$ were calculated, as shown in Fig. 7. Usually, resonant peaks in the bias window contribute to the current. Here, the bias window refers to $[-V / 2$, $V / 2]$. Clearly, either for a- $n \mathrm{PdCl}_{2}-\mathrm{BP}$ device or for $\mathrm{z}-n \mathrm{PdCl}_{2}-\mathrm{BP}$ device, the valence band resonant peaks (below the $E_{\mathrm{f}}$ ) in the

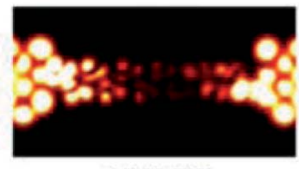

$a$-MLBP

$a-1 \mathrm{PdCl}-\mathrm{BP}$

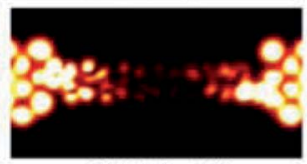

$a-2 \mathrm{PdCl}_{2}-\mathrm{BP}$

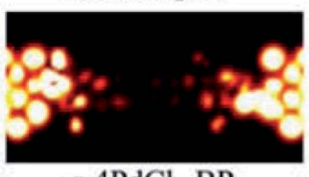

$a-4 \mathrm{PdCl}_{2}-\mathrm{BP}$

Along armchair direction

(a)

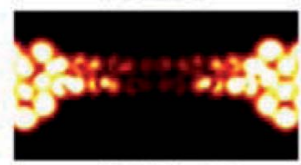

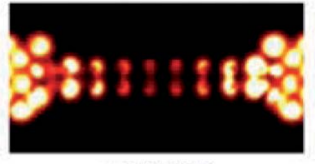

$z$-MLBP

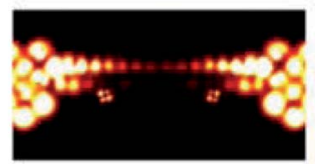
$z-1 \mathrm{PdCl}_{2}-\mathrm{BP}$

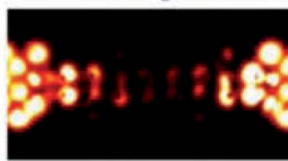

$z-2 \mathrm{PdCl}_{2}-\mathrm{BP}$

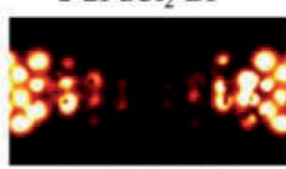

$z-4 \mathrm{PdCl}_{2}-\mathrm{BP}$

Along zigzag direction

(b) bias window shrink gradually with the growing number $n$, again indicating the trap effect of $\mathrm{PdCl}_{2}$ quantum dots. Evidently, the conduction band resonant peaks (above the $E_{\mathrm{f}}$ ) in the bias window of a- $n \mathrm{PdCl}_{2}-\mathrm{BP}$ are much larger than those of $\mathrm{z}-n \mathrm{PdCl}_{2}-$ $\mathrm{BP}$, and thereby the armchair direction gives a higher conductivity than the zigzag, in line with the $I-V$ curves. These features can be further confirmed by the local density of state (LDOS) at the $E_{\mathrm{f}}$ (Fig. 8). Clearly, the LDOS of the scatter regions of both a-

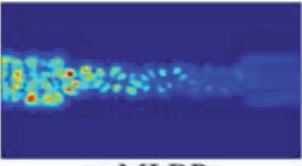

$a$-MLBP

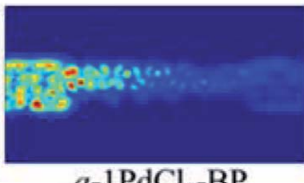

$a-1 \mathrm{PdCl}{ }_{2}-\mathrm{BP}$

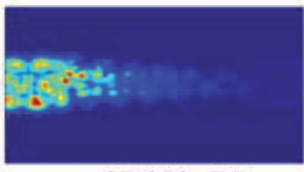

$a-2 \mathrm{PdCl}_{2}-\mathrm{BP}$

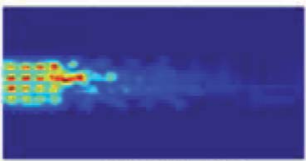

$a-4 \mathrm{PdCl}_{2}-\mathrm{BP}$

Along armchair direction

(a)

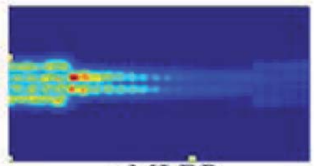

$z$-MLBंP
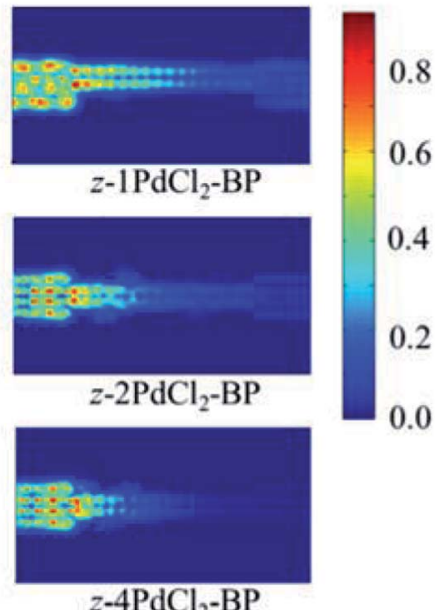

Along zigzag direction

(b)
Fig. 8 The computed LDOS at the Fermi level $E_{f}$ for a-MLBP, z-MLBP, a- $n \mathrm{PdCl}_{2}-\mathrm{BP}$, and $z-n \mathrm{PdCl}_{2}-\mathrm{BP}(n=1,2$, and 4) two-probe devices at $1.0 \mathrm{~V}$ bias voltage.
Fig. 9 The real space scattering states at Fermi energy $E_{f}$ of a-MLBP, $z-M L B P, a-n P_{2 C l}-B P$, and $z-n P_{2 C l}-\mathrm{BP}(n=1,2$, and 4) two-probe devices. 


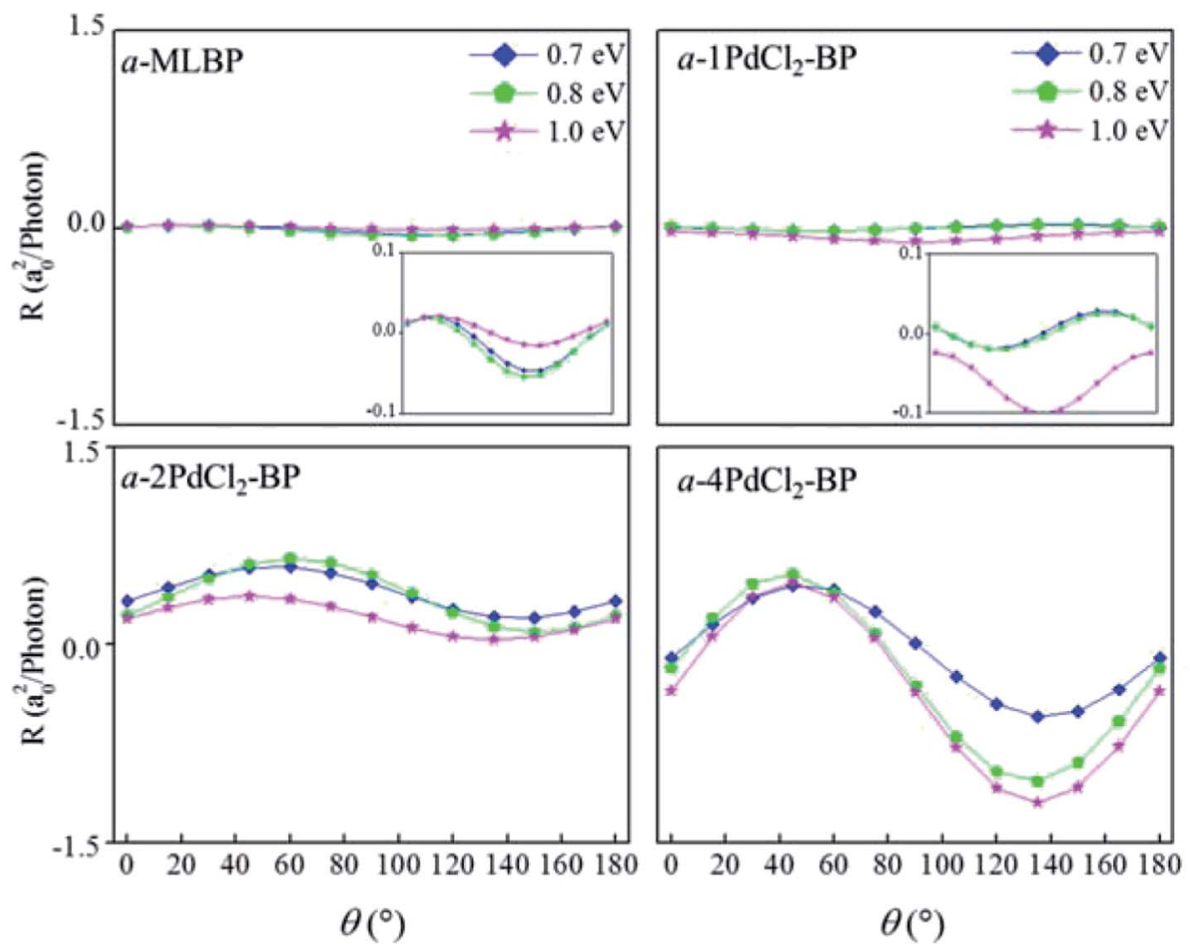

(a) Along armchair direction
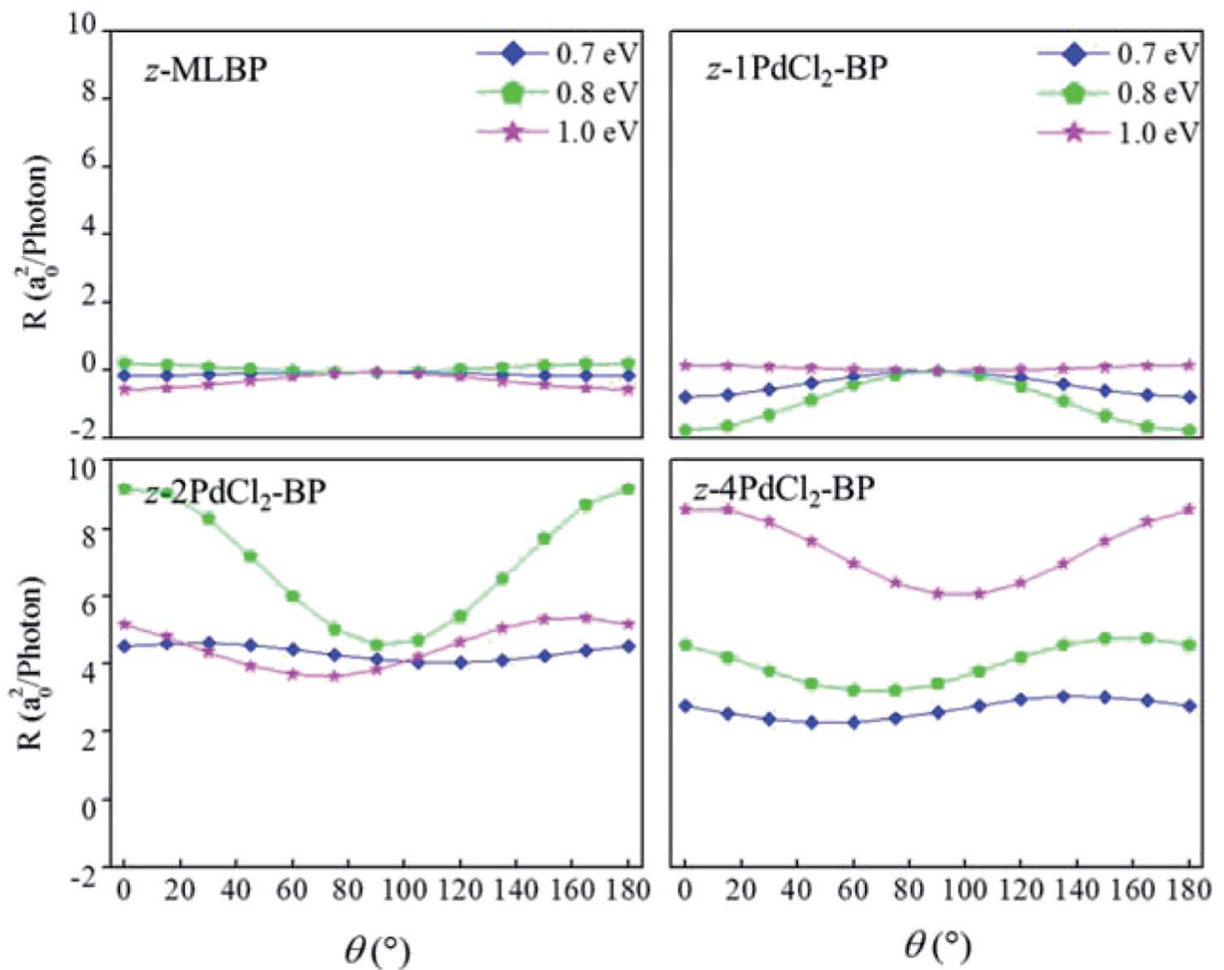

(b) Along zigzag direction

Fig. 10 The calculated photoresponse $R$ for MLBP and $n \mathrm{PdCl}_{2}-\mathrm{BP}(n=1,2$, and 4$)$ two-probe devices irradiated by linearly polarized light. (a) Photoresponse along the armchair direction, and (b) photoresponse along the zigzag direction.

$n \mathrm{PdCl}_{2}-\mathrm{BP}$ and $\mathrm{z}-n \mathrm{PdCl}_{2}$-BP fade away when adding more $\mathrm{PdCl}_{2}$ quantum dots, again indicating the block effect of $\mathrm{PdCl}_{2}$ quantum dots on electron transporting. Compared to a- $n \mathrm{PdCl}_{2}$ -
$\mathrm{BP}$, the block phenomenon in $\mathrm{z}-n \mathrm{PdCl}_{2}-\mathrm{BP}$ is more obvious, correlating well with the higher conductivity for the armchair direction as given by the $I-V$ curves. We also calculated the real- 

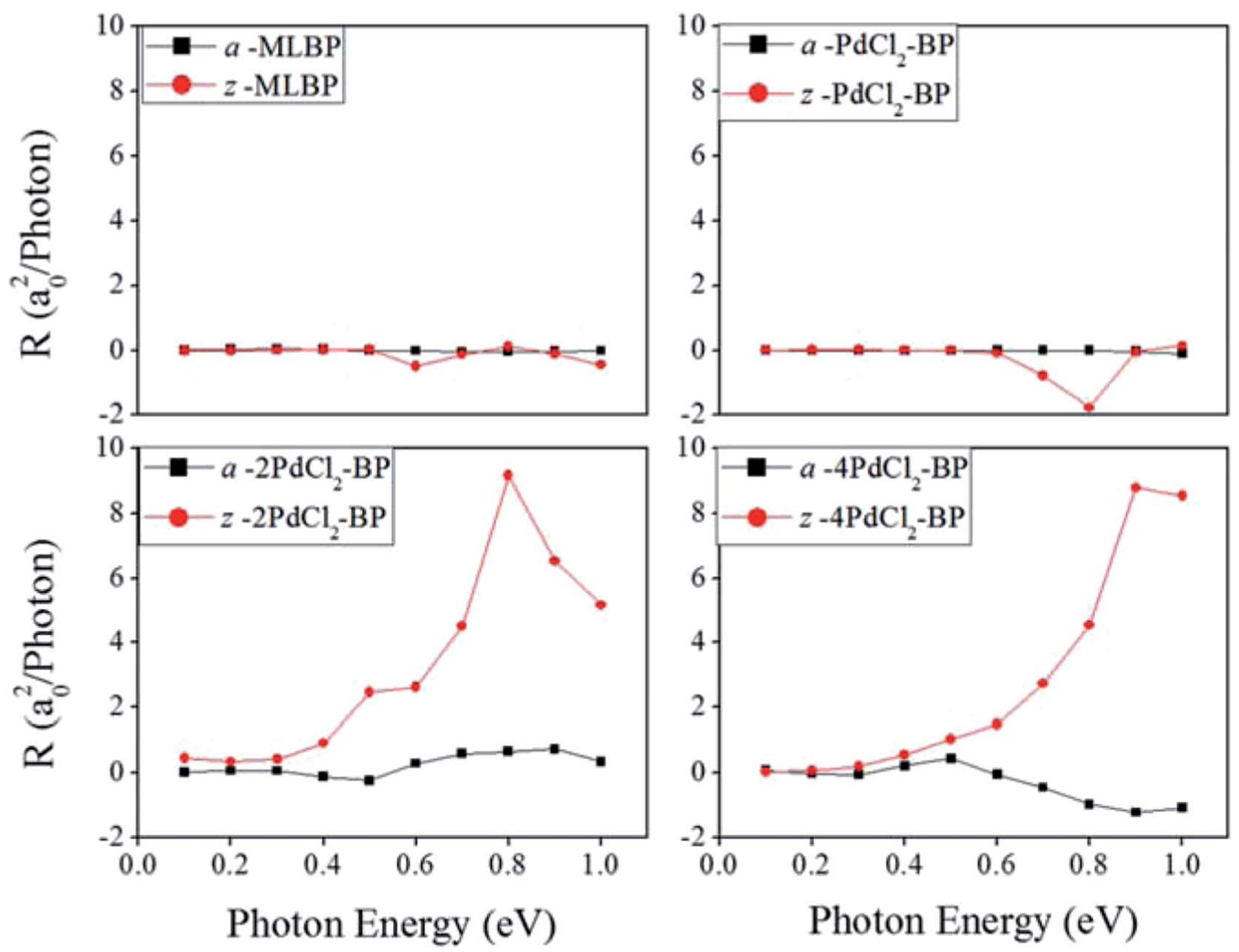

Fig. 11 The calculated maximum photoresponse $R$ for a-MLBP, z-MLBP, a- $n P d C l_{2}-B P$, and z- $n P d C l_{2}-B P(n=1,2$, and 4) two-probe devices irradiated by linearly polarized light.

space scattering states of the systems at the $E_{\mathrm{f}}$ for investigating the transport paths. Fourteen transport channels are obtained (cf. Fig. S1-S8 in ESI $\dagger$ ), indicating that there exist fourteen subbands in the left electrode along the transport direction. Fig. 9 gives the most effective channels for MLBP and $n \mathrm{PdCl}_{2}$-BP $(n=1,2$, and 4$)$. It can be seen that the transport channels tend to be closed if attaching more $\mathrm{PdCl}_{2}$ quantum dots due to their scattering effect, also intuitively explaining the reducing of the conductivity. Moreover, the penetrating channel of $\mathrm{z}-n \mathrm{PdCl}_{2}-\mathrm{BP}$ is weaker at the right side than that of $\mathrm{a}-n \mathrm{PdCl}_{2}-\mathrm{BP}$, giving the evidence that charge carriers transport easily along the armchair direction related to the zigzag direction.

\subsection{Optoelectronic property}

Fig. 2 schematically shows the structures of our devices of $n \mathrm{PdCl}_{2}$-BP $(n=1,2$, and 4) for calculating optoelectronic properties along the armchair and zigzag directions. A linear polarized light was irradiated on the whole scattering region. The applied light has a polarization forming an angle $\theta$ with respect to the transport direction of the MLBP plane. The photoresponses were determined at different $\theta$ for photon energies ranging from 0 to $1.0 \mathrm{eV}$ with an interval of $0.1 \mathrm{eV}$. The photocurrent $I^{(\mathrm{ph})}$ can be obtained from the following formula $(2):^{69}$

$$
I^{(\mathrm{ph})}=\frac{i e}{h} \int \operatorname{Tr}\left\{\Gamma\left[G^{<(\mathrm{ph})}+f(E)\left(G^{>(\mathrm{ph})}-G^{<(\mathrm{ph})}\right)\right]\right\} \mathrm{d} E
$$

The photocurrent of eqn (2) can be separated into three terms: ${ }^{70}$

$$
\begin{aligned}
& I^{(\mathrm{ph})}=\frac{i e}{h} \int\left\{\cos ^{2} \theta \operatorname{Tr}\left\{\Gamma\left[G_{1}^{<(\mathrm{ph})}+f\left(G_{1}>(\mathrm{ph})-G_{1}<(\mathrm{ph})\right)\right]\right\}\right. \\
& +\sin ^{2} \theta \operatorname{Tr}\left\{\Gamma\left[G_{2}^{<(\mathrm{ph})}+f\left(G_{2}{ }^{>(\mathrm{ph})}-G_{2}^{<(\mathrm{ph})}\right)\right]\right\} \\
& \left.+\sin (2 \theta) 2 \operatorname{Tr}\left\{\Gamma\left[G_{3}^{<(\mathrm{ph})}+f\left(G_{3}{ }^{>(\mathrm{ph})}-G_{3}{ }^{<(\mathrm{ph})}\right)\right]\right\}\right\} \mathrm{d} E
\end{aligned}
$$

here $\Gamma$ is the self-energy function, representing the coupling between the central scattering region and the left/right electrode; $G^{<(\mathrm{ph})}$ is the lesser Green's function; $G^{>(\mathrm{ph})}$ is the greater Green's function; $f(E)$ is the Fermi-Dirac distribution function of the left and right electrode. It is easy to check that $I^{(\mathrm{ph})}$ is proportional to the photon flux. Accordingly, the photoresponse function $R$ can be define as

$$
R=\frac{I^{(\mathrm{ph})}}{e F}
$$

versus photon energy with different polarization direction of the light. Here $F$ is the photon flux.

Photoresponses along both armchair and zigzag directions of MLBP and $n \mathrm{PdCl}_{2}-\mathrm{BP}(n=1,2$, and 4$)$ at photo energies of $0.7,0.8$, and $1.0 \mathrm{eV}$ are given in Fig. 10. According to formula (3), the photoresponses correlate directly to the $\sin ^{2} \theta, \cos ^{2} \theta$, and $\sin 2 \theta$ components. Therefore, the photoresponse curves in Fig. 10 take the sine or cosine shapes with $\theta$, which are 
decided by complicated factors such as the geometric symmetry and band structures of the material. The sign of the photoresponse varies with $\theta$ and applied photon energy. This is due to the fact that the sign of the photoresponse is determined by the summation of all activated electrons with different velocity distributions. It is noteworthy that bonding $\mathrm{PdCl}_{2}$ quantum dots is much beneficial for enhancing photoresponses. Regardless of the direction, the maximum photoresponses within the considered photon energies are ordered as $4 \mathrm{PdCl}_{2}-\mathrm{BP}>2 \mathrm{PdCl}_{2}-\mathrm{BP}>1 \mathrm{PdCl}_{2}-\mathrm{BP}>\mathrm{MLBP}$. Values for a$4 \mathrm{PdCl}_{2}-\mathrm{BP}$ and $\mathrm{z}-4 \mathrm{PdCl}_{2}-\mathrm{BP}$ are up to 1.23 and $8.53 \mathrm{a}_{0}{ }^{2}$ /photon, respectively, 22 and 15 times larger than that of a-MLBP (0.0546 $\mathrm{a}_{0}{ }^{2} /$ photon) and z-MLBP $\left(0.579 \mathrm{a}_{0}^{2} /\right.$ photon). This is due to the fact that electrons can be excited easily by the light from the $\mathrm{PdCl}_{2}$ quantum dots which can be demonstrated from the band structures aforementioned. Fig. 11 shows the variation of maximum photoresponses with photo energies. Evidently, the $n \mathrm{PdCl}_{2}-\mathrm{BP}(n=1,2$, and 4$)$ nanostructures have produced photoresponse anisotropy: zigzag direction is about one order of magnitude larger than armchair. All of these fascinating photoresponse properties make these new 2D materials especially attractive for optoelectronic devices.

\section{Summary}

Electronic, transport, and optoelectronic properties of MLBP and $n \mathrm{PdCl}_{2}-\mathrm{BP}(n=1,2$, and 4$)$ are examined by using DFT and NEGF as well as the KNEGF methods. It is found that the $\mathrm{PdCl}_{2}$ quantum dots prefer to locate over the furrow site of MLBP and form a planar quadridentate structure of $\left(\mathrm{Cl}_{\mathrm{Cl}^{-}}^{\mathrm{Cr}_{-}}-\mathrm{P}\right)$. A typical Pd-P coordinate bond is formed. The $\mathrm{PdCl}_{2}$ quantum dots introduce discrete flat levels just above the MLBP valence band and below the $E_{\mathrm{f}}$. The conductivity is much lowered by the $\mathrm{PdCl}_{2}$ grafting, due to the fact that the scatter effect of $\mathrm{PdCl}_{2}$ quantum dots play a major role in the process of electron transporting. For both parent MLBP and functioned $n \mathrm{PdCl}_{2}-\mathrm{BP}$ ( $n=1,2$, and 4), the armchair direction shows higher conductivities than the zigzag. A threshold voltage is found for $4 \mathrm{PdCl}_{2}-\mathrm{BP}$, a valuable clue for exploring current switches. More importantly, functionalization of $\mathrm{PdCl}_{2}$ quantum dots is much beneficial for enhancing photoresponse. Values of photoresponse for $\mathrm{a}-4 \mathrm{PdCl}_{2}-\mathrm{BP}$ and $\mathrm{z}-4 \mathrm{PdCl}_{2}-\mathrm{BP}$ are 22 and 15 times larger than that of a-MLBP and z-MLBP, respectively. A significant photoresponse anisotropy is found for both MLBP and $n \mathrm{PdCl}_{2}-\mathrm{BP}(n=1,2$, and 4$)$, contrary to the conductivity, the zigzag direction shows much stronger photoresponse than the armchair. All of the aforementioned unique properties make this new 2D MLBP based materials especially attractive for both electronic and optoelectronic devices.

\section{Conflicts of interest}

There are no conflicts to declare.

\section{Acknowledgements}

This work was supported by National Natural Science Foundation of China (Grant No. 51473042), Nature Science Foundation of Heilongjiang Province of China (Grant No. B2018007), Harbin foundation for leaders of disciplines (Grant No. 2017RAXXJ002).

\section{References}

1 A. K. Geim and K. S. Novoselov, Nat. Mater., 2007, 6, 183-191. 2 G. Fiori, F. Bonaccorso, G. Iannaccone, T. Palacios, D. Neumaier, A. Seabaugh, S. K. Banerjee and L. Colombo, Nat. Nanotechnol., 2014, 7, 768-779.

3 M. D. Stoller, S. Park, Y. Zhu, J. An and R. S. Ruoff, Nano Lett., 2008, 8, 3498-3502.

4 D. Voiry, J. Yang and M. Chhowalla, Adv. Mater., 2016, 28, 6197-6206.

5 A. H. Castro Neto, F. Guinea, N. M. R. Peres, K. S. Novoselov and A. K. Geim, Rev. Mod. Phys., 2009, 81, 109-162.

6 B. Radisavljevic, A. Radenovic, J. Brivio, V. Giacometti and A. Kis, Nat. Nanotechnol., 2011, 6, 147-150.

7 Y. Jing, X. Zhang and Z. Zhou, WIREs Computational Molecular Science, 2016, 6, 5-19.

8 P. Yasaei, B. Kumar, T. Foroozan, C. Wang, M. Asadi, D. Tuschel, J. E. Indacochea, R. F. Klie and A. SalehiKhojin, Adv. Mater., 2015, 27, 1887-1892.

9 J. Kang, J. D. Wood, S. A. Wells, J. H. Lee, X. Liu, K. S. Chen and M. C. Hersam, ACS Nano, 2015, 9, 3596-3604.

10 Y. Zhang, N. Dong, H. Tao, C. Yan, J. Huang, T. Liu, A. W. Robertson, J. Texter, J. Wang and Z. Sun, Chem. Mater., 2017, 29, 6445-6456.

11 W. Zhao, Z. Xue, J. Wang, X. Zhao and T. Mu, ACS Appl. Mater. Interfaces, 2015, 7, 27608-27612.

12 A. H. Woomer, T. W. Farnsworth, J. Hu, R. A. Wells, C. L. Donley and S. C. Warren, ACS Nano, 2015, 9, 8869-8884.

13 W. Lu, H. Nan, J. Hong, Y. Chen, C. Zhu, Z. Liang, X. Ma, Z. Ni, C. Jin and Z. Zhang, Nano Res., 2014, 7, 853-859.

14 H. Kwon, S. W. Seo, T. G. Kim, E. S. Lee, P. T. Lanh, S. Yang, S. Ryu and J. W. Kim, ACS Nano, 2016, 10, 8723-8731.

15 M. Fortin-Deschênes, P. L. Levesque, R. Martel and O. Moutanabbir, J. Phys. Chem. Lett., 2016, 7, 1667-1674.

16 Y. Chen, G. Jiang, S. Chen, Z. Guo, X. Yu, C. Zhao, H. Zhang, Q. Bao, S. Wen, D. Tang and D. Fan, Opt. Express, 2015, 23, 12823-12833.

17 L. Li, Y. Yu, G. J. Ye, Q. Ge, X. Ou, H. Wu, D. Feng, X. H. Chen and Y. Zhang, Nat. Nanotechnol., 2014, 9, 372-377.

18 S. Das, W. Zhang, M. Demarteau, A. Hoffmann, M. Dubey and A. Roelofs, Nano Lett., 2014, 14, 5733-5739.

19 J. Qiao, X. Kong, Z. X. Hu, F. Yang and W. Ji, Nat. Commun., 2014, 5, 4475.

20 F. Xia, H. Wang and Y. Jia, Nat. Commun., 2014, 5, 4458.

21 A. Castellanos-Gomez, J. Phys. Chem. Lett., 2015, 6, 42804291.

22 J. S. Kim, Y. Liu, W. Zhu, S. Kim, D. Wu, L. Tao, A. Dodabalapur, K. Lai and D. Akinwande, Sci. Rep., 2015, 5, 8989 . 
23 J. Pei, G. Xin, J. Yang, X. Wang, Z. Yu, D. Y. Choi, L. D. Barry and Y. Lu, Nat. Commun., 2016, 7, 10450.

24 D. Yuchen, L. Han, D. Yexin and D. Y. Peide, ACS Nano, 2014, 8, 10035-10042.

25 L. Li, M. Engel, D. B. Farmer, S. J. Han and H. S. P. Wong, ACS Nano, 2016, 10, 4672-4677.

26 K. Gong, L. Zhang, W. Ji and H. Guo, Phys. Rev. B: Condens. Matter Mater. Phys., 2014, 90, 125441.

27 Y. Ma, C. Shen, A. Zhang, L. Chen, Y. Liu, J. Chen, Q. Liu, Z. Li, M. R. Amer, T. Nilges, A. N. Abbas and C. Zhou, ACS Nano, 2017, 11, 7126-7133.

28 C. Han, Z. Hu, L. C. Gomes, Y. Bao, A. Carvalho, S. J. R. Tan, B. Lei, D. Xiang, J. Wu, D. Qi, L. Wang, F. Huo, W. Huang, K. P. Loh and W. Chen, Nano Lett., 2017, 17, 4122-4129.

29 Q. F. Li, X. G. Wan, C. G. Duan and J. L. Kuo, J. Phys. D: Appl. Phys., 2014, 47, 465302.

30 X. Y. Tan, J. H. Wang, Y. Y. Zhu, Y. Zuo and X. Jin, Acta Phys. Sin., 2014, 63, 207301.

31 S. Zhao, W. Kang and J. Xue, J. Mater. Chem. A, 2014, 2, 19046-19052.

32 G. L. Xu, Z. Chen, G. M. Zhong, Y. Liu, Y. Yang, T. Ma, Y. Ren, X. Zuo, X. H. Wu, X. Zhang and K. Amine, Nano Lett., 2016, 16, 3955-3965.

33 G. C. Constantinescu and N. D. Hine, Nano Lett., 2016, 16, 2586-2594.

34 R. A. Doganov, S. P. Koenig, Y. Yeo, K. Watanabe, T. Taniguchi and B. Ozyilmaz, Appl. Phys. Lett., 2015, 106, 083505.

35 P. Zhang, J. Wang and X. M. Duan, Chin. Phys. B, 2016, 25, 037302.

36 Y. Deng, Z. Luo, N. J Conrad, H. Liu, Y. Gong, S. Najmaei, P. M. Ajayan, J. Lou, X. Xu and P. D. Ye, ACS Nano, 2014, 8, 8292-8299.

37 L. Ye, H. Li, Z. Chen and J. Xu, ACS Photonics, 2016, 3, 692699.

38 V. Kumar, J. R. Brent, M. Shorie, H. Kaur, G. Chadha, A. G. Thomas, E. A. Lewis, A. P. Rooney, L. Nguyen, X. Zhong, M. G. Burke, S. J. Haigh, A. Walton, P. D. Mcnaughter, A. A. Tedstone, N. Savjani, C. A. Muryn, P. O'Brien, A. K. Ganguli, D. J. Lewis and P. Sabherwal, ACS Appl. Mater. Interfaces, 2016, 8, 22860-22868.

39 Q. Li, Q. Zhou, X. Niu, Y. Zhao, Q. Chen and J. Wang, J. Phys. Chem. Lett., 2016, 7, 4540-4546.

40 S. P. Koenig, R. A. Doganov, L. Seixas, A. Carvalho, J. Y. Tan, K. Watanabe, T. Taniguchi, N. Yakovlev, A. H. Castro Neto and B. Özyilmaz, Nano Lett., 2016, 16, 2145-2551.

41 V. V. Kulish, O. I. Malyi, C. Persson and P. Wu, Phys. Chem. Chem. Phys., 2015, 17, 992-1000.

42 T. Hu and J. Hong, J. Phys. Chem. C, 2015, 119, 8199-8207.

43 N. Suvansinpan, F. Hussain, G. Zhang, C. H. Chiu, Y. Cai and Y. W. Zhang, Nanotechnology, 2016, 27, 065708.

44 W. Lei, T. Zhang, P. Liu, A. R. Jose, G. Liu and M. Liu, ACS Catal., 2016, 6, 8009-8020.

45 Y. Zhao, H. Wang, H. Huang, Q. Xiao, Y. Xu, Z. Guo, H. Xie, J. Shao, Z. Sun, W. Han, X. F. Yu, P. Li and P. K. Chu, Angew. Chem., Int. Ed., 2016, 55, 5003-5007.
46 E. Alonso, J. Forniés, C. Fortuño, A. Lledós, A. Martín and A. Nova, Inorg. Chem., 2009, 48, 7679-7690.

47 V. I. Bakhmutov, F. Bozoglian, K. Gómez, G. González, V. V. Grushin, S. A. Macgregor, E. Martin, F. M. Miloserdov, M. A. Novikov, J. A. Panetier and L. V. Romashov, Organometallics, 2011, 31, 1315-1328.

48 D. E. Berry, P. Carrie, K. L. Fawkes, B. Rebner and Y. Xing, J. Chem. Educ., 2010, 87, 533-534.

49 L. R. Moore, E. C. Western, R. Craciun, J. M. Spruell and D. A. Dixon, Organometallics, 2008, 27, 576-593.

50 K. Herbst, P. Zanello, M. Corsini, N. D. Amelio, L. Dahleburg and M. Brorson, Inorg. Chem., 2003, 42, 974-981.

51 J. C. W. Folmer, J. A. Turner and B. A. Parkinson, J. Solid State Chem., 1987, 68, 28-37.

52 V. Tran, R. Soklaski, Y. Liang and L. Yang, Phys. Rev. B: Condens. Matter Mater. Phys., 2014, 89, 235319.

53 Y. Du, J. Maassen, W. Wu, Z. Luo, X. Xu and P. D. Ye, Nano Lett., 2016, 16, 6701-6708.

54 R. Fei and L. Yang, Nano Lett., 2014, 14, 2884-2889.

55 J. P. Perdew, K. Burke and M. Ernzerhof, Phys. Rev. Lett., 1996, 77, 3865-3868.

56 M. Brandbyge, J. L. Mozos, P. Ordejon, J. Taylor and K. Stokbro, Phys. Rev. B: Condens. Matter Mater. Phys., 2002, 65, 165401.

57 J. M. Soler, E. Artacho, J. D. Gale, A. Garcia, J. Junquera, P. Ordejon and D. Sanchez-Portal, J. Phys.: Condens. Matter, 2002, 14, 2745-2779.

58 ATK, Version 13.8, atomistix a/s, 2013, www.quantumwise.com.

59 S. Å. Gustafson and G. Dahlquist, Chem. Phys. Lett., 2011, 508, 215-218.

60 J. Taylor, H. Guo and J. Wang, Phys. Rev. B: Condens. Matter Mater. Phys., 2001, 63, 245407.

61 D. Waldron, P. Haney, B. Larade, A. MacDonald and H. Guo, Phys. Rev. Lett., 2006, 96, 166804.

62 T. Takahashi, H. Tokailin, S. Suzuki and I. Shirotani, J. Phys. C: Solid State Phys., 1985, 18, 825-836.

63 M. A. Carvajal, G. P. Miscione, J. J. Novoa and A. Bottoni, Organometallics, 2005, 24, 2086-2096.

64 H. Liu, A. T. Neal, Z. Zhu, Z. Luo, X. Xu, D. Tomanek and P. D. Ye, ACS Nano, 2014, 8, 4033-4041.

65 S. Das, W. Zhang, M. Demarteau, A. Hoffmann, M. Dubey and A. Roelofs, Nano Lett., 2014, 14, 5733-5739.

66 Y. Du, C. Ouyang, S. Shi and M. Lei, J. Appl. Phys., 2010, 107, 093718.

67 T. H. Oosterkamp, T. Fujisawa, W. G. V. D. Wiel, K. Ishibashi, R. V. Hijman, S. Tarucha and L. P. Kouwenhoven, Nature, 1998, 395, 873-876.

68 B. G. Streetman and S. K. Banerjee, Solid State Electronic Devices, Sixth Edition, Prentice Hall, 2006.

69 L. Zhang, K. Gong, J. Chen, L. Liu, D. Xiao and H. Guo, Phys. Rev. B: Condens. Matter Mater. Phys., 2014, 90, 195428.

70 Y. Xie, L. Zhang, Y. Zhu, L. Liu and H. Guo, Nanotechnology, 2015, 26, 455202 . 